\title{
Increased Computer Use is Associated with Trunk Asymmetry That Negatively Impacts Health-Related Quality of Life in Early Adolescents
}

\author{
Mei-Chun Cheung $\mathbb{D}^{\prime}$ \\ Janelle SK Lai (D) \\ Joanne Yip (1D ${ }^{2}$ \\ Jason Pui Yin Cheung $\mathbb{D}^{3}$ \\ 'Department of Social Work, The \\ Chinese University of Hong Kong, \\ Hong Kong SAR, China; ${ }^{2}$ Institute of \\ Textiles and Clothing, The Hong Kong \\ Polytechnic University, Hong Kong SAR, \\ China; ${ }^{3}$ Department of Orthopaedics and \\ Traumatology, The University of \\ Hong Kong, Hong Kong SAR, China
}

Correspondence: Mei-Chun Cheung Department of Social Work, The Chinese University of Hong Kong, Shatin, New Territories, Hong Kong SAR, China

Tel $+852-39431862$

Fax +852-260350I8

Email meichun@swk.cuhk.edu.hk
Purpose: This study aimed to investigate the effects of trunk asymmetry on the healthrelated quality of life of early adolescents and to identify daily activities that were associated with trunk asymmetry in this cohort.

Methods: This study included 200 early adolescents (52 male and 148 female) aged 10 to 14 years in Hong Kong. Among them, 100 adolescents were considered to have trunk asymmetry with angle of trunk rotation $\geq 5^{\circ}$ and one or more physical signs on visual inspection. The 36-Item Short Form Health Survey was used to measure the eight scales under the physical and mental domains of the health-related quality of life. The adolescents reported their average daily durations spent (1) using a computer; (2) using a smartphone; (3) watching television, videos or DVDs; (4) doing homework; and (5) doing physical exercise. Independent samples $t$-tests, chi-square $\left(\chi^{2}\right)$ tests or Mann-Whitney $U$-tests were performed to compare the health-related quality of life and the average daily duration of daily activities between early adolescents with and without trunk asymmetry. Logistic regression was performed to investigate the odds ratios of daily activities for trunk asymmetry.

Results: Compared with early adolescents without trunk asymmetry, those with trunk asymmetry had a lower health-related quality of life in some of the physical domains, namely, bodily pain and general health, and all mental domains, namely, vitality (energy/ fatigue), social functioning, role limitation due to emotional problems and mental health ( $p<$ $0.05)$. Use of computer was found to be significantly associated with trunk asymmetry in early adolescents $(\mathrm{OR}=1.63,95 \% \mathrm{CI}[1.23,2.14])$.

Conclusion: Our results indicate that increased computer use is associated with trunk asymmetry, which negatively impacts the health-related quality of life in early adolescents.

Keywords: trunk asymmetry, computer, smartphone, health-related quality of life, early adolescents

\section{Introduction}

Posture is defined as the position of the body at a given point of time. ${ }^{1}$ A correct posture is defined by a straight spine without forward, backward, left, or right body inclination. ${ }^{2}$ Having a correct posture is important as it allows an individual to maintain the musculoskeletal balance of their anatomical structure with maximum stability, minimal stress and minimal energy consumption. ${ }^{3,4}$ However, early adolescents who are undergoing a period of dynamic development and pubertal growth spurts are highly prone to incorrect or poor posture, ${ }^{5}$ which means that the body is not in an upright position such that musculoskeletal balance and normal 
morphological functions cannot be maintained. ${ }^{6-8}$ In fact, previous studies have shown that incorrect or poor posture is more common among early adolescents than among children, and this trend has been growing over the past decades. For instance, in 2003 in Czech Republic, the prevalence of poor posture was significantly higher, at $40.6 \%$, in 1190 early adolescents aged 11 years, compared with $33 \%$ in 1097 children aged 7 years. ${ }^{9}$ In 2015 in Poland, more than 50\% of 236 early adolescents aged 12 to 13 years had incorrect posture. ${ }^{10} \mathrm{~A}$ recent populationbased study in China reported an even higher prevalence of incorrect posture at $64.8 \%$ in 518,890 early Chinese adolescents aged 10 to 15 years; ${ }^{8}$ again, this was significantly higher than the prevalence of $41.3 \%$ in children aged less than 10 years in that study.

Postural abnormalities, including an incorrect or poor posture, are associated with many musculoskeletal symptoms, such as soreness and pain in body regions such as the neck, shoulder, back and thoracic spine, which are commonly reported among children and adolescents. ${ }^{11-14}$ Therefore, many studies have investigated possible risk factors for postural abnormalities in children and adolescents to reduce or even prevent its occurrence at an early age. Demographic characteristics such as increasing age, weight, body mass index (BMI), and amount of physical activity, including reduced levels of physical activity and extended periods of time in a seated position, have commonly been reported as risk factors for postural abnormalities in children and adolescents. ${ }^{6,9,15-17}$ For example, being obese or underweight has been found to likely contribute to incorrect ${ }^{18}$ or poor posture. ${ }^{9}$ Children and adolescents who do not play sports or who spend their leisure time in passive activities are more likely to have poor posture compared with those who play sports regularly or spend their leisure time actively. ${ }^{6,9}$ Specifically, Kratěnová et $\mathrm{al}^{9}$ reported that children and adolescents who spent time in front of a television or computer for 2 hours or more daily were 1.24-times more likely to have poor posture than have good posture, but these findings could not be replicated in other studies. ${ }^{6,19}$ In a recent study, adolescents aged 10 to 18 years who engaged in sustained smartphone use for 20 minutes exhibited evident postural deviations that caused progressive muscle overload in the posterior neck. ${ }^{20}$ Given that individuals' postures tend to vary according to their habits ${ }^{2}$ and early adolescents often spend extended periods of time in their daily life in a seated position for computer and smartphone use, as well as for other daily activities, the negative influence of such habit on postural abnormalities has recently received increasing research attention and should not be overlooked.

Although access to a computer has increased among adolescents aged 13 to 17 years by only $1 \%$ from $87 \%$ in 2014-2015 to $88 \%$ in 2018, there has been a substantial increase of $22 \%$ in the ownership of or access to a smartphone in this cohort, from $73 \%$ in $2014-2015^{21}$ to $95 \%$ in $2018 .^{22}$ Computers and smartphones have thus become the most frequently used technological devices among adolescents. In view of the rising popularity of computers and smartphones in this population, it is worthwhile to explore whether prolonged use of computers and smartphones contributes to the increasing prevalence of posture abnormalities among early adolescents. Indeed, postural problem is a potential risk factor for developing musculoskeletal disorders, such as scoliosis, during adolescence, ${ }^{7,23,24}$ and adolescents with scoliosis, compared to those without it, tend to experience more physical health problems, higher levels of pain, poorer psychosocial functioning, lower selfimage and poorer quality of life. ${ }^{25-27}$ Therefore, given these significant effects of postural abnormalities on various health-related aspects, we aimed to explore the influence of postural abnormalities on the health-related quality of life in early adolescents.

Specifically, as a correct posture involves a straight spine, ${ }^{2}$ trunk asymmetry - that is, asymmetry in height between the right and left sides of the upper body-is a very common postural abnormality in early adolescents. ${ }^{28-30}$ Asymmetry in shoulder height is the most common incorrect posture among Chinese adolescents. ${ }^{13}$ To measure trunk asymmetry, the most commonly used method is clinical examination using a scoliometer combined with the Adam's forward bend test (FBT), which is the easiest and most reliable noninvasive method to quantify the angle of trunk rotation $(\text { ATR })^{31-34}$ with good specificity and sensitivity. ${ }^{35,36}$ We hypothesized that early adolescents with trunk asymmetry have a poorer health-related quality of life than those without asymmetry, with the probability of trunk asymmetry being higher among early adolescents who use computers and smartphones for longer durations. Moreover, potential factors that have been investigated in previous studies on postural abnormalities, ${ }^{6,9,15-20}$ including demographic factors such as age, weight, and BMI; external factors such as school bag weight; and daily activities such as the time spent doing homework, the time spent performing physical activity, and the amount of screen 
time, are also considered to identify the association between such factors and the presence of trunk asymmetry in early adolescents.

\section{Materials and Methods}

\section{Participants}

A total of 200 early adolescents (52 male and 148 female) aged 10 to 14 years were selected from a school screening program jointly conducted by the Hong Kong Polytechnic University and the Chinese University of Hong Kong at local primary/secondary schools at the Hong Kong Polytechnic University from 2017 to 2021. The inclusion and exclusion criteria of the study were determined following a literature review. ${ }^{17,37}$ The eligibility criteria included the ability to 1) maintain a standing position without help, 2) understand and comply with instructions, 3) read and write in Chinese, and 4) complete the questionnaire properly. Early adolescents with known diagnoses of musculoskeletal or developmental disorders that may affect the spinal curvature, surgical intervention of the spine, or mental and/or psychological disabilities were excluded. During screening, early adolescents underwent upper body posture assessment and were asked to complete the Hong Kong version ${ }^{38-41}$ of the 36-item Short Form Health Survey (SF-36), ${ }^{42,43}$ which assessed their health-related quality of life. They were also asked to complete a customized questionnaire on potential factors that have been investigated in previous studies on postural abnormalities. ${ }^{6,9,15-20}$ All data were collected in the presence of the early adolescents' parents or guardians. All early adolescents participated voluntarily, and informed assent and written informed consent for participation were obtained from the early adolescents and their parents, respectively, prior to the study. The demographic data of the participants is provided in Table 1. This study was conducted in compliance with the principles outlined in the Declaration of Helsinki of the World Medical Association Assembly. The research protocol was approved by the Human Subjects Ethics Sub-committee of the Hong Kong Polytechnic University, the Survey and Behavioral Research Ethics Committee, and the Joint Chinese University of Hong Kong-New Territories East Cluster Clinical Research Ethics Committee of the Chinese University of Hong Kong. All methods were performed in accordance with the relevant guidelines and regulations.

\section{Assessment of Upper Body Posture}

During screening, assessment of upper body posture of all early adolescents was conducted by an independent experienced prosthetist-orthotist $(\mathrm{P} \& \mathrm{O})$, who was blinded to the hypotheses of the study, using visual inspection of physical signs, Adam's FBT and measurement of the ATR using a scoliometer (OSI, Orthopaedic Systems Inc., Hayward, CA, USA). ${ }^{44}$ With reference to the limits for postural asymmetry proposed by Vercauteren et $\mathrm{al}^{45}{ }^{45}$ the visual inspection of trunk asymmetry and spinal curvature in the median plane involved checking for the presence of head tilt, shoulder asymmetry (high and low shoulder), hip and pelvic obliquity (hip/pelvic tilt), and deviation of the spinal curvature from the median plan while the participants were in a standing upright position. During the FBT, the participants were requested to slowly bend 90 degrees forward at the waist, with their feet placed together, knees straight, chin tucked to the chest, arms hanging down freely and palms held together. ${ }^{46-49}$ The scoliometer was placed over the spinous processes and glided along the back surface of the thoracic and lumbar spine to measure the ATR while the participants performed the Adam's FBT. Depending on the location of the thoracic rotational prominence or lumbar flank prominence, the participants were asked to bend forward until the hump became apparent. The scoliometer was then placed at the level of the most prominent aspect of the hump, with the " 0 " mark centered over the spine. The ATR, as measured by a scoliometer in the thoracic and lumbar regions, was then recorded. ${ }^{31,35}$ Measurement of the ATR using a scoliometer has been described in the literature as a reliable, noninvasive measure of trunk asymmetry, ${ }^{31-34}$ and its cutoff point is usually between $5^{\circ}$ and $7^{\circ} \cdot{ }^{33,37,50}$ In the study, an ATR $\geq 5^{\circ}$ with one or more observable physical signs of postural problems on visual inspection was considered as indicative of trunk asymmetry. $^{28}$

Of the 1294 early adolescents who were screened, 100 (7.7\%; 26 males and 74 females) were identified to have trunk asymmetry, while the remaining early adolescents either did not demonstrate trunk asymmetry or demonstrated mild trunk asymmetry with an ATR of $<5^{\circ}$. Given that a previous study demonstrated the sex effect on trunk asymmetry (with trunk asymmetry being more common in females than in males), ${ }^{28}$ a control group with trunk symmetry having a similar sex distribution and sample size was used for comparison. As a result, 100 early adolescents, who were matched according to $\operatorname{sex}\left(\chi^{2}(1)=0.00, p=1.00\right)$ by intention and age $[t(198)=-0.99, p=0.32]$, were stratified by sex and 
Table I Demographic Information of Early Adolescents with and without Trunk Asymmetry

\begin{tabular}{|c|c|c|c|c|c|c|c|c|c|c|}
\hline \multirow[b]{2}{*}{ Variable } & \multicolumn{4}{|c|}{ Without $(n=100)$} & \multicolumn{4}{|c|}{ With $(n=100)$} & \multirow[b]{2}{*}{$t / \chi^{2}$} & \multirow[b]{2}{*}{$p$} \\
\hline & $\mathbf{N}$ & Mean & SD & Range & $\mathbf{N}$ & Mean & SD & Range & & \\
\hline Age (years) & 100 & 11.94 & 0.63 & $11-13$ & 100 & 12.05 & 0.92 & $10-14$ & -0.99 & 0.32 \\
\hline \multicolumn{11}{|l|}{ Sex } \\
\hline Male & 26 & & & & 26 & & & & 0.00 & 1.00 \\
\hline Female & 74 & & & & 74 & & & & & \\
\hline Height (cm) & 100 & 154.75 & 7.52 & $\mid 34.00-174.00$ & 100 & $|54.8|$ & 7.32 & $133.50-175.00$ & -0.06 & 0.95 \\
\hline Weight (kg) & 100 & 45.18 & 11.29 & $26.00-87.70$ & 100 & 43.13 & 7.54 & $27.50-60.70$ & 1.51 & 0.13 \\
\hline BMI & 100 & 18.64 & 3.30 & |3.24-29.64 & 100 & 17.89 & 2.19 & | 3.47-24.49 & 1.89 & 0.06 \\
\hline Weight of school bag (kg) & 89 & 4.07 & 2.10 & $0.50-11.00$ & 93 & 4.25 & 2.21 & $1.00-10.00$ & -0.56 & 0.58 \\
\hline Angle of thoracic rotation & & & & & & & & & 147.83 & 0.00 \\
\hline Normal (ATR: 0-2º & 100 & & & & 15 & & & & & \\
\hline Rotate to the left (ATR: $\left.3^{\circ}-4^{\circ}\right)$ & - & & & & 2 & & & & & \\
\hline Rotate to the right (ATR: $3^{\circ}-4^{\circ}$ ) & - & & & & 3 & & & & & \\
\hline Rotate to the left $\left(\right.$ ATR $\left.\geq 5^{\circ}\right)$ & - & & & & 12 & & & & & \\
\hline Rotate to the right $\left(\operatorname{ATR} \geq 5^{\circ}\right)$ & - & & & & 68 & & & & & \\
\hline Angle of lumbar rotation & & & & & & & & & 63.16 & 0.00 \\
\hline Normal (ATR: 0-2) & 100 & & & & 52 & & & & & \\
\hline Rotate to the left (ATR: $3^{\circ}-4^{\circ}$ ) & - & & & & 7 & & & & & \\
\hline Rotate to the right (ATR: $3^{\circ}-4^{\circ}$ ) & - & & & & 11 & & & & & \\
\hline Rotate to the left $\left(\right.$ ATR $\left.\geq 5^{\circ}\right)$ & - & & & & 20 & & & & & \\
\hline Rotate to the right $\left(A T R \geq 5^{\circ}\right)$ & - & & & & 10 & & & & & \\
\hline Head tilt & & & & & & & & & 16.22 & 0.00 \\
\hline Absence & 100 & & & & 85 & & & & & \\
\hline Presence & - & & & & 15 & & & & & \\
\hline High and low shoulder & & & & & & & & & 53.17 & 0.00 \\
\hline Absence & 100 & & & & 58 & & & & & \\
\hline Presence & - & & & & 42 & & & & & \\
\hline Spinal curvature & & & & & & & & & 18.58 & 0.00 \\
\hline Absence & 100 & & & & 83 & & & & & \\
\hline Presence & - & & & & 17 & & & & & \\
\hline Hip/Pelvic Tilt & & & & & & & & & 35.29 & 0.00 \\
\hline Absence & 100 & & & & 70 & & & & & \\
\hline Presence & - & & & & 30 & & & & & \\
\hline
\end{tabular}

randomly selected from the pool of early adolescents with an ATR of between $0^{\circ}$ and $2^{\circ}$ and no physical signs of postural asymmetry (Table 1).

\section{Measures}

\section{Health-Related Quality of Life}

The Hong Kong version ${ }^{38-41}$ of the SF-36 $6^{42,43}$ was used to measure the participants' health-related quality of life in the physical and mental domains. The scale has been adapted to and validated for over 40 countries $^{51}$ and commonly used in adolescent populations, ${ }^{52-54}$ with norm reference criteria available from 14 countries, ${ }^{51}$ including Hong Kong. ${ }^{39,40}$ The SF-36 consists of 35 questions that are summarized into eight multi-item scales under two domains, and one self-reported question which is related to health transition as compared to one year ago. The four scales related to the physical domain of the health-related quality of life are physical functioning (10 items), role 
limitation due to physical health problems (4 items), bodily pain ( 2 items) and general health ( 5 items), whereas the four scales related to the mental domain of the healthrelated quality of life are vitality (energy/fatigue; 4 items), social functioning ( 2 items), role limitation due to emotional problems ( 3 items) and mental health (5 items). ${ }^{55}$ The scores for all items in each of the eight scales are summed and transformed according to the standard scoring algorithm of the SF- $36^{43}$ into a standardized scale score for each scale. The scale scores range from 0 to 100 , with a higher score indicating a better health-related quality of life. As this study does not focus on changes in health over time, the self-reported health transition item, which is an independent question that is not used to score any of the eight multi-item scales as stated in the manual, ${ }^{43}$ was not used for analysis in this study.

\section{Questionnaire on Demographic Information and Daily Activities}

All of the participants were asked to complete a questionnaire on demographic information and daily activities customized for this research that gathered data on age, height, body weight, school-bag weight and various daily activities that may affect upper body posture based on previous studies. ${ }^{6,9,15-20}$ For daily activities, the participants were asked to rate the average daily duration over the past week spent (1) using a computer; (2) using a smartphone; (3) watching television, videos and DVDs; and (4) doing homework on the following scale: (a) never, (b) less than 1 hour, (c) 1 to 2 hours, (d) 3 to 4 hours and (e) more than 4 hours; and (5) doing physical exercises on the following scale: (a) never, (b) half an hour, (c) 1 hour and (d) more than 1 hour. The scales for the average daily duration spent performing these activities were adapted from the study by Kratěnová et al, ${ }^{9}$ in which early adolescents spent an average of less than 1 hour per day performing physical exercise and an average of 2 hours per day watching TV or using the computer. The questionnaire has been used in our studies, ${ }^{56,57}$ in which the scales generally achieved a normal distribution for the data being collected. Height and body weight were measured and recorded by a research assistant during screening and used to calculate the BMI using the formula of weight in kilograms divided by height in meters squared $\left(\mathrm{kg} / \mathrm{m}^{2}\right)$.

\section{Data Processing and Analysis}

All statistical analyses were performed using the Statistical Package for Social Sciences (SPSS, Version 25.0, IBM Corp, USA). Demographic variables, daily activities, and the physical and mental domains of the health-related quality of life were compared between early adolescents with and without trunk asymmetry using independent samples $t$-tests, chi-square $\left(\chi^{2}\right)$ tests or Mann-Whitney $U$-tests. Logistic regression was performed to investigate the odds ratios of daily activities for trunk asymmetry. A $p$-value of less than 0.05 was considered statistically significant.

\section{Results \\ Demographic Characteristics}

Given that some early adolescents were not sure of the weight of their school bag, some of them (symmetry, $\mathrm{n}=11$; asymmetry, $n=7$ ) did not provide the corresponding information in the questionnaire. As shown in Table 1, the results of independent-samples $t$-tests did not reveal statistically significant differences in height $(t(198)=-0.06, p=0.95)$, weight $(t(198)=$ $1.51, p=0.13)$, BMI $(t(198)=1.89, p=0.06)$, or school bag weight $(t(190)=-0.56, p=0.58)$ between early adolescents with and without trunk asymmetry. Therefore, two groups of early adolescents were matched in terms of height, weight, BMI, and school bag weight.

\section{Prevalence of Postural Abnormalities Among Early Adolescents with Trunk Asymmetry}

Among the 100 early adolescents with trunk asymmetry, the prevalence of thoracic and lumbar rotation $\geq 5^{\circ}$ was $80 \%$ and $30 \%$, respectively. Most of these participants ( 90 of 100) had a thoracic or lumbar rotation of $\geq 5^{\circ}$, while the remaining had an ATR $\geq 5^{\circ}$ in both the thoracic and lumbar regions. The most frequently found physical sign of trunk asymmetry was shoulder asymmetry (42\%), followed by followed by hip/pelvic tilt (30\%), spinal curvature (17\%) and head tilt (15\%).

A comparison of postural abnormalities between male and female participants revealed that the prevalence of head tilt and spinal curvature was similar between males and females. The prevalence of lumbar rotation was significantly higher in males than in females $(65.4 \%$ vs $\left.41.9 \%, \chi^{2}(1)=4.25, p=0.04\right)$. In contrast, the prevalence of shoulder asymmetry was significantly higher in females than in males $\left(50.0 \%\right.$ vs $\left.19.2 \%, \chi^{2}(1)=7.48, p=0.01\right)$, as was the prevalence of hip/pelvic tilt $\left(36.5 \%\right.$ vs $11.5 \%, \chi^{2}$ $(1)=5.70, p=0.02)$ and thoracic rotation $(89.2 \%$ vs $\left.73.2 \%, \chi^{2}(1)=3.92, p=0.05\right)$. 


\section{Influence of Trunk Asymmetry on the Health-Related Quality of Life}

Descriptive statistics on the scales of SF-36 for early adolescents with and without trunk asymmetry are provided in Table 2. Compared with early adolescents with trunk symmetry, those with trunk asymmetry reported a significantly lower mean score for six out of the eight scales under the physical and mental domains of the health-related quality of life. The results of independent samples $t$-tests revealed statistically significant differences between the two groups in the physical scales of bodily pain $\left(M_{\text {diff }}=5.08,95 \%\right.$ CI $[1.30,8.86], t(198)=2.65$, $p=0.01)$ and general health $\left(M_{\text {diff }}=9.41,95 \%\right.$ CI [5.01, 13.81], $t(198)=4.22, p<0.001)$, and in the mental scales of vitality (energy/fatigue) $\left(M_{\text {diff }}=10.70,95 \%\right.$ CI [5.99, 15.41], $t$ $(198)=4.48, p<0.001)$, social functioning $\left(M_{\text {diff }}=5.25,95 \%\right.$ CI $[1.24,9.26], t(198)=2.58, p=0.01)$, role limitation due to emotional problems $\left(M_{\text {diff }}=9.00,95 \%\right.$ CI $[3.42,14.58], t(198)$ $=3.18, p=0.002)$ and mental health $\left(M_{\text {diff }}=12.84,95 \% \mathrm{CI}\right.$ $[8.65,17.03], t(198)=6.04, p<0.001)$. In contrast, no significant differences were found in the physical scales of physical functioning and role limitation due to physical health problems between the two groups $(p>0.05)$.

\section{Association Between Trunk Asymmetry and Daily Activities}

Given the statistically significant differences in the physical and mental domains of the health-related quality of life between early adolescents with and without trunk asymmetry, we further compared the two groups with respect to the average durations spent daily over the past week in some daily activities that may be associated with trunk asymmetry, including (1) using a computer; (2) using a smartphone; (3) watching television, videos and DVDs; (4) doing homework; and (5) doing physical exercise.

\section{Computer Use}

The average daily durations of computer use over the past week among early adolescents with and without trunk asymmetry are shown in Figure 1. The number of early adolescents who never used a computer or used a computer for an average daily duration of less than 1 hour to up to 2 hours over the past week was higher in the trunk symmetry group $(\mathrm{n}=96)$ than in the trunk asymmetry group $(\mathrm{n}=71)$. However, the number of early adolescents who used a computer for an average daily duration of 3 to 4 hours over the past week in the trunk asymmetry group $(\mathrm{n}=11)$ was more than double that in the trunk symmetry group $(n=4)$. Notably, computer use for an average daily duration of more than 4 hours over the past week was reported only among early adolescents with trunk asymmetry, occurring in nearly one-sixth of the participants in this group $(n=16)$. The results of a Mann-Whitney $U$-test indicated that the average daily duration of computer use was significantly higher in early adolescents with trunk asymmetry (mean rank: 109.71) than in those with trunk symmetry (mean rank: $89.50 ; U=3899.50, z=-2.62, p=0.009)$. To further identify whether computer use predicted trunk asymmetry among early adolescents, a binary logistic regression analysis was conducted. The results showed that computer use accounted for a significant amount of variance in trunk asymmetry [likelihood ratio $x^{2}(1)=13.09, p<0.001$ ]. The Nagelkerke pseudo- $R^{2}$ further showed that approximately $8.5 \%$ of the variance in trunk asymmetry was accounted for by computer use. The model was able to correctly classify $45.9 \%$ of the early adolescents who

Table 2 Descriptive Statistics on the Scales of SF-36 for Early Adolescents with and without Trunk Asymmetry

\begin{tabular}{|c|c|c|c|c|c|c|c|c|c|c|}
\hline \multirow[b]{2}{*}{ Variable } & \multicolumn{4}{|c|}{ Without $(n=100)$} & \multicolumn{4}{|c|}{ With $(n=100)$} & \multirow[b]{2}{*}{$t / \chi^{2}$} & \multirow[b]{2}{*}{$\mathbf{p}$} \\
\hline & $\mathbf{N}$ & Mean & SD & Range & $\mathbf{N}$ & Mean & SD & Range & & \\
\hline \multicolumn{11}{|l|}{ SF-36 Scales } \\
\hline Physical functioning & 100 & 96.85 & 10.91 & $30.00-100.00$ & 100 & 96.35 & 12.08 & $5.00-100.00$ & 0.31 & 0.76 \\
\hline Role limitation due to physical problems & 100 & 98.50 & 8.57 & $25.00-100.00$ & 100 & 96.25 & 11.98 & $25.00-100.00$ & 1.53 & 0.13 \\
\hline Bodily pain & 100 & 95.26 & 12.03 & $0.00-100.00$ & 100 & 90.18 & 14.90 & $42.00-100.00$ & 2.65 & 0.01 \\
\hline General health & 100 & 87.65 & 12.24 & $47.00-100.00$ & 100 & 78.24 & 18.65 & $40.00-100.00$ & 4.22 & 0.00 \\
\hline Vitality (energy/fatigue) & 100 & 83.20 & $\mid 4.31$ & $30.00-100.00$ & 100 & 72.50 & 19.11 & $10.00-100.00$ & 4.48 & 0.00 \\
\hline Social functioning & 100 & 95.63 & 12.61 & $0.00-100.00$ & 100 & 90.38 & 15.98 & $37.50-100.00$ & 2.58 & 0.01 \\
\hline Role limitation due to emotional problems & 100 & 97.00 & 12.62 & $0.00-100.00$ & 100 & 88.00 & 25.30 & $0.00-100.00$ & 3.18 & 0.00 \\
\hline Mental health & 100 & 85.28 & 12.43 & $32.00-100.00$ & 100 & 72.44 & 17.23 & $12.00-100.00$ & 6.04 & 0.00 \\
\hline
\end{tabular}

Abbreviation: SF-36, 36-Item Short Form Health Survey. 


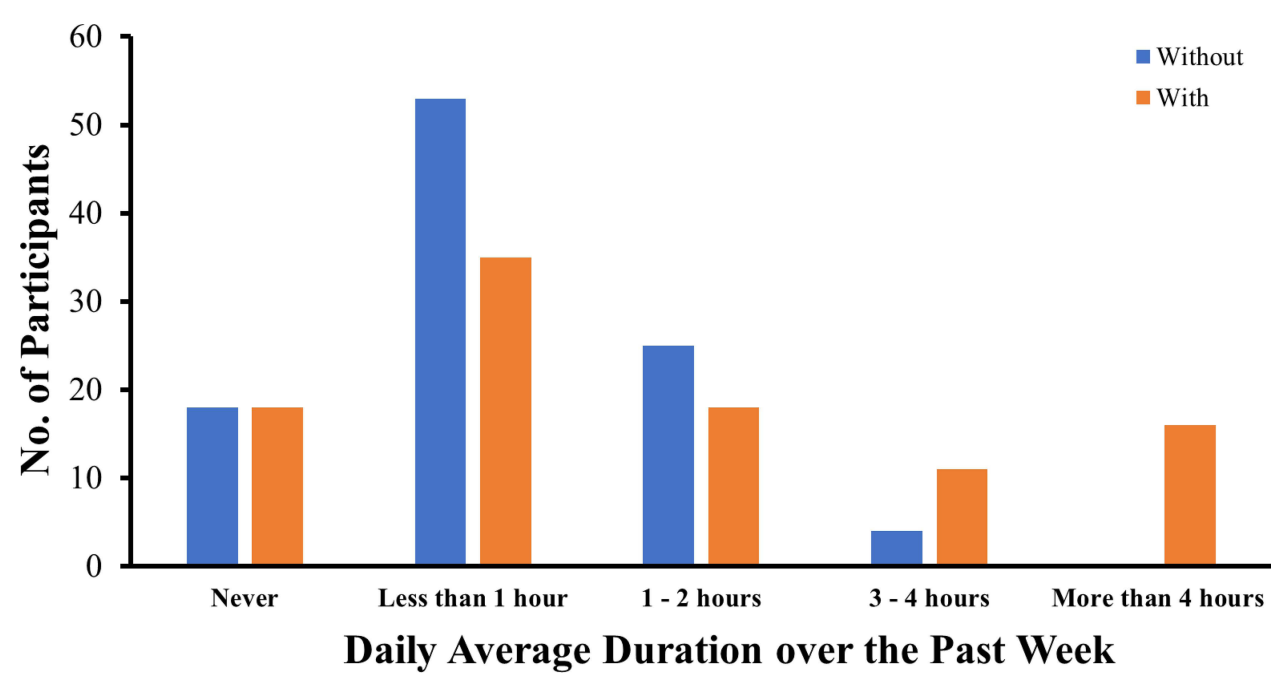

Figure I Average daily durations of computer use over the past week among early adolescents with and without trunk asymmetry.

reported trunk asymmetry and $71 \%$ of those who reported trunk symmetry, with an overall success rate of $58.6 \%$. The use of a computer was a significant predictor of trunk asymmetry $(b=0.49, S E=0.14, p<0.001)$. The odds ratio for computer use was 1.63 , with a $95 \%$ confidence level of $[1.23,2.14]$, which suggests that early adolescents who used a computer for less than 1 hour to more than 4 hours were 1.63 times more likely to report trunk asymmetry than those who did not use a computer.

\section{Smartphone Use}

As shown in Figure 2, most of the early adolescents with trunk symmetry $(n=85)$ or trunk asymmetry $(n=76)$ never used a smartphone or used a smartphone for an average daily duration of less than 1 hour to 2 hours over the past week. Though the number of early adolescents who used smartphone for an average daily duration of 3 to 4 hours and more than 4 hours was slightly higher in the trunk asymmetry group ( $\mathrm{n}=14$ and $\mathrm{n}=7$, respectively) than in the trunk symmetry group ( $n=11$ and $n=4$, respectively), the results of a Mann-Whitney $U$-test did not indicate a statistically significant difference in the duration of smartphone use between the two groups $(U=4849.50, z=-0.00$, $p=0.99$ ).

\section{Time Spent in Watching Television, Videos and DVDs} As shown in Figure 3, most of the early adolescents with trunk symmetry $(n=93)$ or trunk asymmetry $(n=87)$ never watched television, videos and DVDs or watched these for an average daily duration of less than 1 hour to up to 2 hours over the past week. Though the number of early adolescents who watched television, videos and

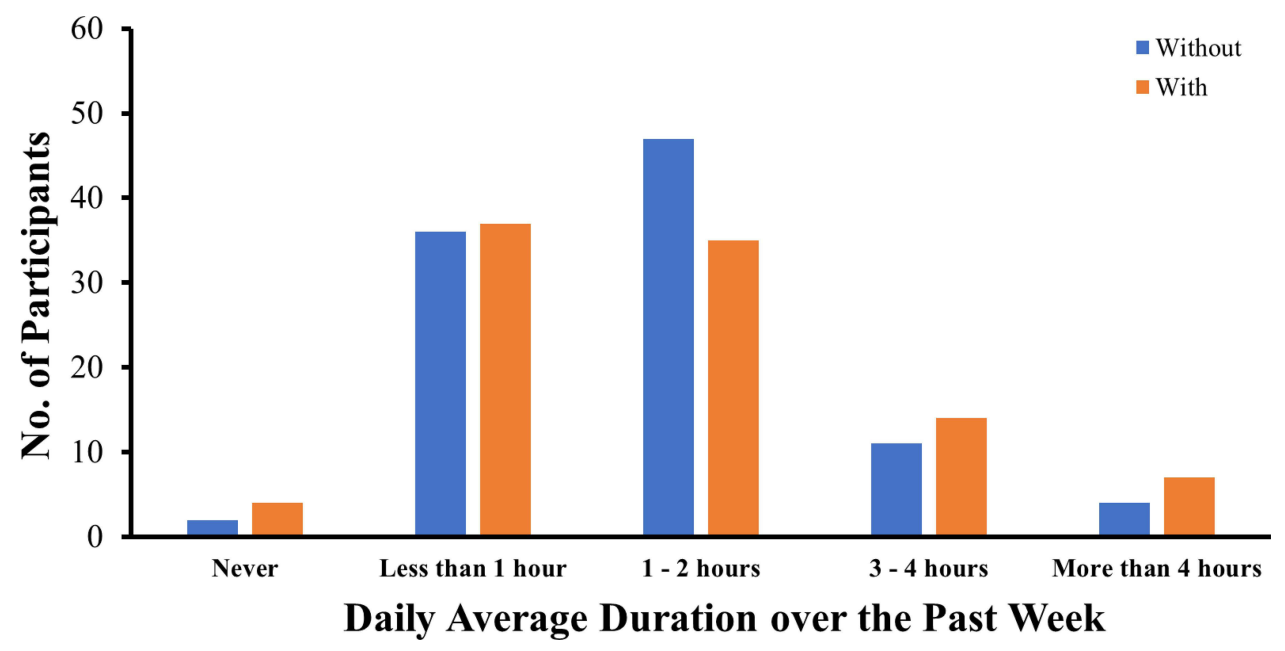

Figure 2 Average daily durations of smartphone use over the past week among early adolescents with and without trunk asymmetry. 


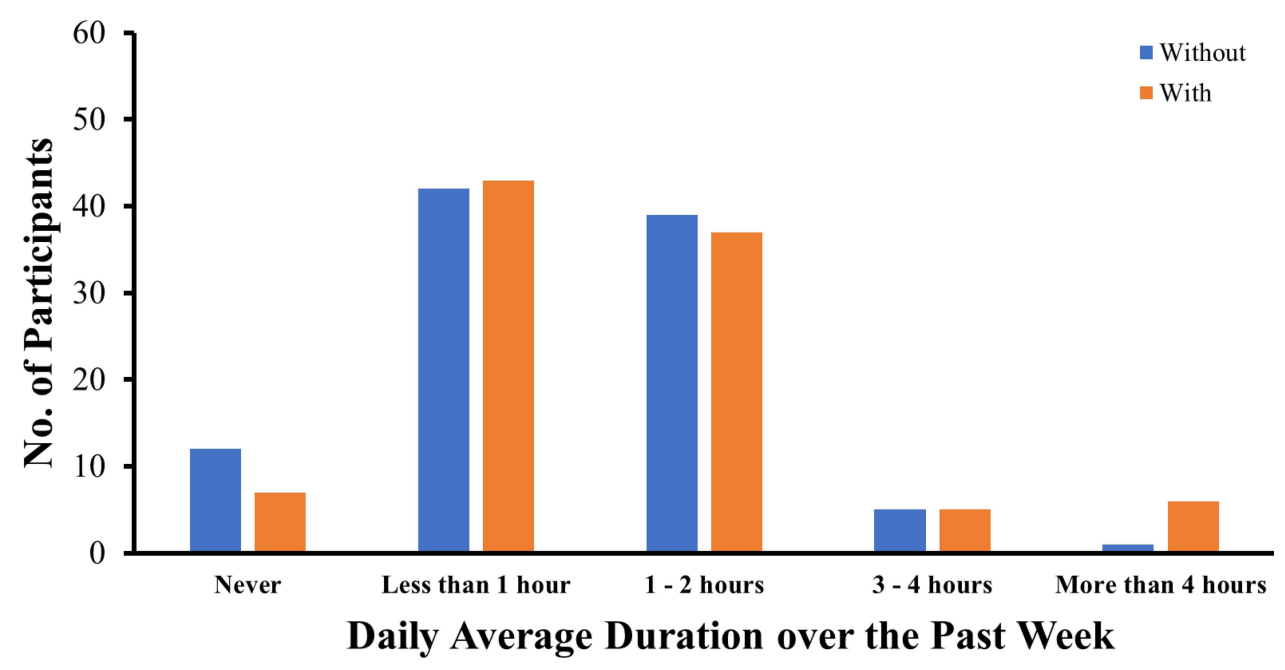

Figure 3 Average daily durations spent in watching television, videos and DVDs over the past week among early adolescents with and without trunk asymmetry.

DVDs for more than 4 hours was six-times higher in the trunk asymmetry group $(n=6)$ than in the trunk symmetry group ( $\mathrm{n}=1)$, the results of a Mann-Whitney $U$-test did not indicate a statistically significant difference in the time spent in watching television, videos and DVDs between the two groups $(U=4453.00, z=-1.07, p=0.28)$.

\section{Time Spent in Doing Homework}

Over half of the early adolescents with trunk symmetry $(\mathrm{n}=57)$ or trunk asymmetry $(\mathrm{n}=55)$ spent an average daily duration of 1 to 2 hours in doing homework over the past week (Figure 4). Moreover, the number of early adolescents who spent no time to up to 4 hours in doing homework over the past week was similar between the trunk symmetry and trunk asymmetry groups. Though the number of early adolescents who spent an average daily duration of more than 4 hours in doing homework was 9 times higher in the trunk asymmetry group $(n=9)$ than in the trunk symmetry group $(\mathrm{n}=1)$, the results of a MannWhitney $U$-test did not indicate a statistically significant difference in the time spent in doing homework between the two groups $(U=4701.00, z=-0.28, p=0.78)$.

\section{Time Spent in Doing Physical Exercises}

Most of the early adolescents with trunk symmetry $(\mathrm{n}=90)$ or trunk asymmetry $(\mathrm{n}=90)$ spent at least half an hour performing physical exercise daily over the past week (Figure 5), indicating that early adolescents with trunk asymmetry spent a similar amount of time on such activities as those with trunk symmetry. Consistently, the results of a Mann-Whitney $U$-test did not indicate a statistically significant difference in the time spent in

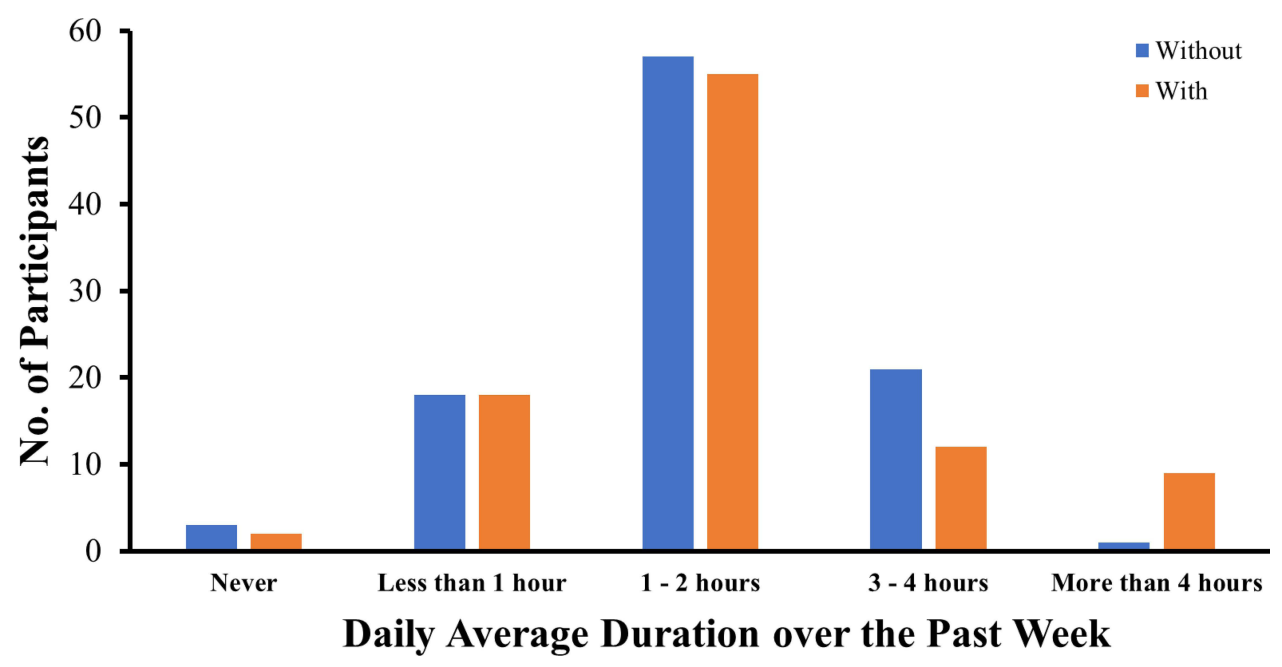

Figure 4 Average daily durations spent in doing homework over the past week among early adolescents with and without trunk asymmetry. 


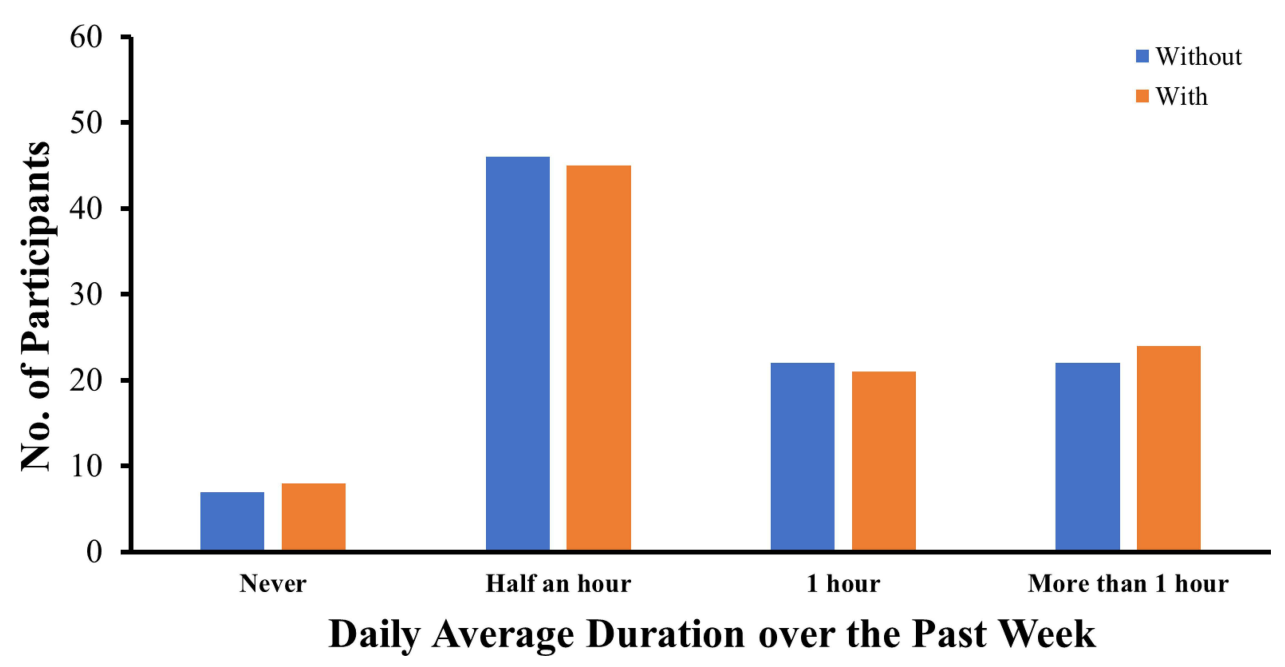

Figure 5 Average daily durations spent in doing physical exercises over the past week among early adolescents with and without trunk asymmetry.

doing physical exercise between the two groups $(U=4720.00, z=-0.09, p=0.93)$.

\section{Discussion}

This study investigated the effects of trunk asymmetry on the physical and mental domains of the health-related quality of life, and of various daily activities on trunk asymmetry, among early adolescents in Hong Kong. Consistent with our hypothesis, early adolescents with trunk asymmetry had a lower health-related quality of life in two scales of the physical domain and all scales of the mental domain, compared with early adolescents with trunk symmetry. In particular, except for physical functioning and role limitation due to physical health problems, statistically significant differences were found in all other scales, including bodily pain, general health, vitality (energy/fatigue), social functioning, role limitation due to emotional problems and mental health, between early adolescents with trunk symmetry and those with trunk asymmetry. The findings are in line with previous research that investigated the negative associations between posture abnormalities, musculoskeletal symptoms and disorders, ${ }^{11-14}$ and a range of physical health problems and psychosocial difficulties that are commonly reported among children and adolescents with posture abnormalities. ${ }^{5,7,23-25,27}$ Given that the average daily duration of computer use was significantly longer for early adolescents with trunk asymmetry than for those without trunk asymmetry, it could be argued that the differences in the health-related quality of life may be due to the difference in the daily duration of computer use between these two groups. To rule out this possibility, another study was carried out to explore the influence of computer use on the health-related quality of life in early adolescents. The results show that the average daily duration of computer use had a significantly negative association with only two scales of the mental domain: vitality (energy/fatigue) and mental health (unpublished study). Therefore, the differences in the two scales of the physical domain and other scales of the mental domain were very likely due to trunk asymmetry and cannot be attributed to the average daily duration of computer use.

Our study found a statistically significant association between trunk asymmetry and the average daily duration of computer use. Specifically, early adolescents who used a computer for an average daily duration of less than 1 hour to over 4 hours were found to be 1.63-times more likely to have trunk asymmetry than those who did not use a computer. While most of the early adolescents with trunk symmetry $(\mathrm{n}=96)$ in our sample did not use a computer or tended to use a computer for less than 1 hour to up to 2 hours, there were more early adolescents with trunk asymmetry $(n=27)$ than those without trunk asymmetry $(n=4)$ who tended to spend an average daily duration of 3 hours or more on computer. In addition, computer use for more than four hours was only found among early adolescents with trunk asymmetry, accounting for around $16 \%$ of this group. Although the success rate of the predictive model in this study was not very high, the findings add to our knowledge on postural abnormalities by showing that prolonged computer use is likely associated with a higher probability of trunk asymmetry in early adolescents. The 
findings further support the importance of identifying the daily activities that are potential factors associated with postural abnormalities among early adolescents. At present, there is no conclusive recommendation on the desirable duration of screen time for early adolescents, but it has been shown that a daily screen time duration exceeding 2.5 hours is significantly associated with a lower quality of life and a range of negative health outcomes, ${ }^{58}$ which is comparable to the trend of the average daily duration of computer use found in this study. Studies have also reported that a long duration of computer use is associated with poor posture ${ }^{9}$ and increasing odds of lower back pain among adolescents. ${ }^{15,59-61}$ Therefore, it is important to delineate an acceptable average daily duration of computer use for early adolescents to reduce the probability of trunk asymmetry or other postural abnormalities.

Contrary to our hypothesis, other screen time activities, such as the use of a smartphone and time spent watching television, videos and DVDs did not show significant association with trunk asymmetry in early adolescents. These findings are also contrary to the association between screen time activities and musculoskeletal concerns reported in previous studies. ${ }^{62,63}$ Consistent with our study, one study that investigated the effects of various screen time activities on bodily pain reported that the risk of neck and lower back pain was associated with computer use, but not with the duration of mobile phone use or television watching. ${ }^{60}$ Unexpectedly, the average daily duration of other daily activities, such as the time spent doing homework and physical exercises, did not show significant difference between early adolescents with and without trunk asymmetry. These results also differ from those of existing studies on the negative influence of sedentary life habits and reduced levels of physical activity on posture abnormalities. ${ }^{6,9,15}$ Our results show that around $7-8 \%$ of early adolescents did not participate in any physical exercise or sports every day. Although early adolescents spent the least amount of time performing physical exercise or sports compared with other daily activities, most of the early adolescents with trunk symmetry $(n=90)$ or trunk asymmetry $(n=90)$ still spent at least half an hour performing physical exercise every day in addition to the mandatory physical education classes, which vary in duration between schools (around 80 to 100 minutes each week in the Hong Kong school system). Indeed, the overall average daily duration spent performing physical exercise every day was in parallel to that in a study by Kratěnová et al, ${ }^{9}$ in which early adolescents spent an average of less than 1 hour per day performing physical exercise. Regarding the average daily duration of doing homework, there was no significant difference between the two groups, with a median value of 1-2 hours every day. It is thus speculated that the non-significant difference between early adolescents with trunk symmetry and trunk asymmetry in these two daily activities in this study may be related to the adoption of a correct body posture when doing homework ${ }^{64}$ and the regularity of doing physical exercise ${ }^{6}$ among early adolescents. Specifically, the differences between the effects of computer use and other daily activities on trunk asymmetry may be due to differences in the characteristics of habitual posture adopted during specific daily activities, and not the activities per se. The postural habits of adolescents differ by screen-based activity type, ${ }^{65}$ and these habits may significantly influence trunk asymmetry. Indeed, a computer, whether it is a laptop or a desktop, remains immobile on the lap or desk, entailing the individual to maintain the same static posture while performing repetitive upper extremity motions, such as typing on the keyboard and using the mouse. ${ }^{66}$ Early adolescents usually adopt a slumped posture with head flexion during computer use, which is associated with chronic pain, especially in the lower back area. ${ }^{65,67}$ As a result, it is conceivable that the postures adopted by early adolescents while performing other daily activities, such as using a smartphone, watching TV or doing homework, may not be as restricted as those taken when using a computer.

Of the 1294 early adolescents who were screened, 100 $(7.7 \% ; 26$ males and 74 females) were identified to have trunk asymmetry, while the remaining early adolescents either did not demonstrate trunk asymmetry or demonstrated mild trunk asymmetry with an ATR of $<5^{\circ}$. The percentage of early adolescents with trunk asymmetry (males: $2.01 \%$, females: $5.72 \%$ ) was relatively comparable to that found in the study of Balla and Hanțiu ${ }^{28}$ in Romania. These authors showed that in a sample of 487 early adolescents (260 males and 227 females) aged 10 to 15 years, $1.84 \%$ of early male adolescents and $7.28 \%$ of early female adolescents had trunk asymmetry. Another study of 2071 children and adolescents (1099 boys and 972 girls) aged 5 to 18 years also demonstrated that trunk asymmetry is more common in females than in males, ${ }^{30}$ consistently suggesting that the influence of sex should be considered when studying trunk asymmetry. A comparison of males and females did not reveal sex differences in the duration of time spent daily on different activities $(p>$ 
0.05). Therefore, the higher prevalence rate of trunk asymmetry in females cannot be attributed to the duration of time spent daily on different daily activities, but the stage of development (eg, puberty) may play a role, as puberty starts earlier in females than in males. To determine the effects of puberty on trunk asymmetry, a larger sample of early adolescents from different age groups should be recruited to examine if the main effect of sex-that is, the higher percentage of cases of trunk asymmetry-is consistently observed in females from different age groups, or if an interaction effect of sex and age is found. Consistent with a previous study, ${ }^{30}$ trunk asymmetry was much more common to the right than to the left. Given that a positive association has been reported between the laterality of trunk asymmetry and hand dominance in school children, ${ }^{68,69}$ the possibility that our finding was also related to hand dominance cannot be ruled out. While it is worthwhile to perform additional studies on early adolescents to further confirm the association between the laterality of trunk asymmetry and hand dominance, clinical evaluation of trunk asymmetry should include the evaluation of hand dominance laterality in the future.

The results of our study should be considered along with the following limitations and future research possibilities. As this study investigated the average durations that early adolescents spent daily in various daily activities, we were not able to elucidate the postures that early adolescents adopted during these daily activities or the regularity of these activities, although these factors may contribute to trunk asymmetry. Further investigation is warranted to explore the independent and combined influences of the duration and regularity of various daily activities, as well as of the postures adopted during these daily activities, on trunk asymmetry among early adolescents to further understand the nature of factors that may affect posture in this population. In addition, this study only investigated a few daily activities that are commonly performed by early adolescents; thus, a wider range of daily activities can be investigated in the future to identify more potential factors for trunk asymmetry in this population. Although the assessment of upper body posture was performed by an independent and experienced $\mathrm{P} \& \mathrm{O}$, subjective measurement bias, which is difficult to avoid completely, cannot be ruled out. For instance, as self-report measures were used in this study, discrepancies between self-reported and actual daily durations of daily activities may exist. In future studies, log data on various daily activities may be collected via smart devices to generate more comprehensive and objective observations. In this study, more than $70 \%$ of the participants were female. Thus, our findings may be more reflective of the situation of early female adolescents in Hong Kong than of early male adolescents. The result regarding the higher prevalence of shoulder asymmetry and hip/pelvic tilt among female than males should be considered in light of this limitation. Finally, this study used a cross-sectional design, which makes it difficult to examine the influence of the developmental level on trunk asymmetry, draw causal inferences, and generalize the findings to a broader population. Given that pubertal growth spurts are highly prone to postural abnormalities, ${ }^{5}$ it is possible that the stage of development (eg, puberty) may also play a role in the development or progression of trunk asymmetry, ${ }^{5}$ especially in females. In addition, it is conceivable that early adolescents with trunk asymmetry and lower health-related quality of life may spend more time in front of a computer, could worsen trunk asymmetry and health-related quality of life. A longitudinal study is strongly recommended to investigate the change in the severity of trunk asymmetry, healthrelated quality of life, and duration of daily activities over time and to determine the causal effects between trunk asymmetry, health-related quality of life, and daily activities among early adolescents, as well as the influence of puberty on trunk asymmetry.

Despite these limitations, this study demonstrated the negative influence of trunk asymmetry on the physical and mental domains of the health-related quality of life in early adolescents and the negative association between computer use and trunk asymmetry in this cohort. At a time such as the COVID-19 pandemic, when the use of computers for education, social and entertainment purposes has increased drastically, this study wishes to raise awareness among early adolescents, parents and schools about the importance of being mindful of the time spent by early adolescents in using computers, the postures they adopt and the negative impact of trunk asymmetry on their health-related quality of life.

\section{Acknowledgments}

This work was supported by funding from the Research Grant Council - General Research Fund granted to The Chinese University of Hong Kong (MC, 14607519) and The Hong Kong Polytechnic University (JY, 15208018), and the Innovation and Technology Fund - Innovation and Technology Support Program - Public Sector Trial Scheme 
granted to The Hong Kong Polytechnic University (JY, ITT/025/19GP).

\section{Disclosure}

Professor Mei-Chun Cheung reports grants from Research Grant Council - General Research Fund, during the conduct of the study. Dr Joanne Yip reports grants from Research Grant Council - General Research Fund, and Innovation and Technology Fund, during the conduct of the study. The authors report no other conflicts of interest in this work.

\section{References}

1. Pastorelli F, Pasquetti P. Biomechanical analysis and rehabilitation in athletes. Clin Cases Miner Bone Metab. 2013;10(2):96.

2. Kim D, Cho M, Park Y, Yang Y. Effect of an exercise program for posture correction on musculoskeletal pain. J Phys Ther Sci. 2015;27 (6):1791-1794. doi:10.1589/jpts.27.1791

3. Carini F, Mazzola M, Fici C, et al. Posture and posturology, anatomical and physiological profiles: overview and current state of art. Acta Biomed. 2017;88(1):11-16. doi:10.23750/abm.v88i1.5309

4. Griegel-Morris P, Larson K, Mueller-Klaus K, Oatis CA. Incidence of common postural abnormalities in the cervical, shoulder, and thoracic regions and their association with pain in two age groups of healthy subjects. Phys Ther. 1992;72(6):425-431. doi:10.1093/ptj/ 72.6 .425

5. Biernat M, Bąk-Sosnowska M. The impact of body posture on self-image and psychosocial functioning during adolescence. Pediatr I Med Rodz. 2018;14(3):282-285. doi:10.15557/ PiMR.2018.0031

6. Latalski M, Bylina J, Fatyga M, et al. Risk factors of postural defects in children at school age. Ann Agric Environ Med. 2013;20 (3):583-587.

7. Yan B, Lu X, Qiu Q, Nie G, Huang Y. Association between incorrect posture and adolescent idiopathic scoliosis among Chinese adolescents: findings from a large-scale population-based study. Front Pediatr. 2020;8:548. doi:10.3389/fped.2020.00548

8. Yang L, Lu X, Yan B, Huang Y. Prevalence of incorrect posture among children and adolescents: finding from a large population-based study in China. iScience. 2020;23(5):101043. doi:10.1016/j.isci.2020.101043

9. Kratěnová J, Žejglicová K, Malý M, Filipová V. Prevalence and risk factors of poor posture in school children in the Czech Republic. $J \quad$ Sch Health. 2007;77(3):131-137. doi:10.1111/j.17461561.2007.00182.x

10. Motylewski S, Zientala A, Pawlicka-Lisowska A, PoziomskaPiątkowska E. Assessment of body posture in 12- and 13-year-olds attending primary schools in Pabianice. Pol Merkur Lekarski. 2015;39(234):368-371.

11. Briggs AM, Smith AJ, Straker LM, Bragge P. Thoracic spine pain in the general population: prevalence, incidence and associated factors in children, adolescents and adults. A systematic review. $B M C$ Musculoskelet Disord. 2009;10(1):77. doi:10.1186/1471-2474-10-77

12. Cho CY, Hwang IS, Chen CC. The association between psychological distress and musculoskeletal symptoms experienced by Chinese high school students. J Orthop Sport Phys Ther. 2003;33(6):344-353. doi:10.2519/jospt.2003.33.6.344

13. Cho CY. Survey of faulty postures and associated factors among Chinese adolescents. J Manipulative Physiol Ther. 2008;31 (3):224-229. doi:10.1016/j.jmpt.2008.02.003
14. Dolphens M, Cagnie B, Coorevits P, et al. Sagittal standing posture and its association with spinal pain. Spine. 2012;37(19):1657-1666. doi:10.1097/BRS.0b013e3182408053

15. Quka N, Stratoberdha D, Selenica R. Risk factors of poor posture in children and its prevalence. Acad J Interdiscip Stud. 2015;4 (3):97-102. doi:10.5901/ajis.2015.v4n3p97

16. Demirbüken İ, Özgül B, Timurtaş E, et al. Demographic characteristics related to body posture in early adolescence. $J$ Exerc Ther Rehabil. 2016;3(3):84-89.

17. Ozdemir S, Gencbas D, Tosun B, Bebis H, Sinan O. Musculoskeletal pain, related factors, and posture profiles among adolescents: a cross-sectional study from Turkey. Pain Manag Nurs. 2021;22:522-530. doi:10.1016/j.pmn.2020.11.013

18. Maciałczyk-Paprocka K, Stawińska-Witoszyńska B, Kotwicki T, et al. Prevalence of incorrect body posture in children and adolescents with overweight and obesity. Eur J Pediatr. 2017;176 (5):563-572. doi:10.1007/s00431-017-2873-4

19. Brink Y, Louw Q, Grimmer K, Jordaan E. The spinal posture of computing adolescents in a real-life setting. BMC Musculoskelet Disord. 2014;15(1):212. doi:10.1186/1471-2474-15-212

20. Hanphitakphong P, Thawinchai N, Poomsalood S, Jin Z. Effect of prolonged continuous smartphone gaming on upper body postures and fatigue of the neck muscles in school students aged between 1018 years. Cogent Eng. 2021;8(1):1890368. doi:10.1080/ 23311916.2021.1890368

21. Lenhart A, Duggan M, Perrin A, Stepler R, Rainie H, Parker K. Teens, Social Media \& Technology Overview 2015. Pew Research Center; 2015.

22. Anderson M, Jiang J. Teens, Social Media \& Technology 2018. Pew Research Center; 2018.

23. Nault ML, Allard P, Hinse S, et al. Relations between standing stability and body posture parameters in adolescent idiopathic scoliosis. Spine. 2002;27(17):1911-1917. doi:10.1097/00007632200209010-00018

24. Nissinen M, Heliövaara M, Seitsamo J, Poussa M. Trunk asymmetry, posture, growth, and risk of scoliosis. Spine. 1993;18(1):8-13. doi:10.1097/00007632-199301000-00002

25. Cheung MC, Yip J, Fok LH, Kwok G. Health-related quality of life in adolescents with mild scoliosis. Proceedings of the 31st International Academic Conference. London: International Institute of Social and Economic Sciences; 2017. doi:10.20472/IAC.2017.031.016.

26. Cheung MC, Yip J, Fok LH, Kwok G. Prevalence of pain and mood symptoms in female adolescents with early signs of scoliosis. Paper Presented at 2018 International Health Conference; 2018 Jun 28-30; London, United Kingdom.

27. Tones M, Moss N, Polly DW. A review of quality of life and psychosocial issues in scoliosis. Spine. 2006;31(26):3027-3038. doi:10.1097/01.brs.0000249555.87601.fc

28. Balla BJ, Hanţiu I. Trunk asymmetry at children aged $10-15$ years: relation between amount of asymmetry and risk factors. Timisoara Phys Educ Rehabil J. 2017;10(19):114-118. doi:10.1515/tperj-20170027

29. Hazebroek-Kampschreur AAJM, Hofman A, van Dijk AP, van Linge B. Prevalence of trunk abnormalities in eleven-year-old schoolchildren in Rotterdam, The Netherlands. J Pediatr Orthop. 1992;12 (4):480-484. doi:10.1097/01241398-199207000-00012

30. Grivas TB, Vasiliadis ES, Koufopoulos G, Segos D, Triantafyllopoulos G, Mouzakis V. Study of trunk asymmetry in normal children and adolescents. Scoliosis. 2006;1(1):19. doi:10.1186/1748-7161-1-19

31. Qiao J, Xu L, Zhu Z, et al. Inter- and intraobserver reliability assessment of the axial trunk rotation: manual versus smartphone-aided measurement tools. BMC Musculoskelet Disord. 2014;15(1):343. doi:10.1186/1471-2474-15-343

32. Bunnell WP. Outcome of spinal screening. Spine. 1993;18 (12):1572-1580. doi:10.1097/00007632-199309000-00001 
33. Amendt LE, Ause-Ellias KL, Eybers JL, Wadsworth CT, Nielsen DH, Weinstein SL. Validity and reliability testing of the scoliometer ${ }^{\circledR}$. Phys Ther. 1990;70(2):108-117. doi:10.1093/ptj/70.2.108

34. Rigo M. Patient evaluation in idiopathic scoliosis: radiographic assessment, trunk deformity and back asymmetry. Physiother Theory Pract. 2011;27(1):7-25. doi:10.3109/09593985.2010.503990

35. Côté P, Kreitz BG, Cassidy JD, Dzus AK, Martel J. A study of the diagnostic accuracy and reliability of the scoliometer and Adam's forward Bend test. Spine. 1998;23(7):796-802. doi:10.1097/ 00007632-199804010-00011

36. Oetgen ME, Heyer JH, Kelly SM. Scoliosis screening. J Am Acad Orthop Surg. 2021;29(9):370-379. doi:10.5435/JAAOS-D-20-00356

37. Navarro IJRL, Candotti CT, do Amaral MA, Dutra VH, Gelain GM, Loss JF. Validation of the measurement of the angle of trunk rotation in photogrammetry. J Manipulative Physiol Ther. 2020;43(1):50-56. doi:10.1016/j.jmpt.2019.05.005

38. Lam C. Reliability and construct validity of the Chinese (Hong Kong) SF-36 patients in primary care. Hong Kong Pract. 2003;25(10):468-475.

39. Lam C, Gandek B, Ren XS, Chan MS. Tests of scaling assumptions and construct validity of the Chinese (HK) version of the SF-36 Health Survey. $J$ Clin Epidemiol. 1998;51(11):1139-1147. doi:10.1016/S0895-4356(98)00105-X

40. Lam C, Lauder IJ, Lam TP, Gandek B. Population based norming of the Chinese (HK) version of the SF-36 health survey. Hong Kong Pract. 1999;21(10):460-470.

41. Lam C, Fong D, Lauder IJ, Lam TPD. The effect of health-related quality of life (HRQOL) on health service utilisation of a Chinese population. Soc Sci Med. 2002;55(9):1635-1646. doi:10.1016/S02779536(01)00296-9

42. Ware JE, Sherbourne CD. The MOS 36-item short-form health survey (SF-36): I. Conceptual framework and item selection. Med Care. 1992;30(6):473-483. doi:10.1097/00005650-199206000-00002

43. Ware JE, Snow KK, Kosinski M, Gandek B. SF-36 Health Survey: Manual and Interpretation Guide. The Health Institute, New England Medical Center; 1993.

44. Adams W. Lectures on the Pathology and Treatment of Lateral and Other Forms of Curvature of the Spine. London: J \& A. Churchill; 1882.

45. Vercauteren M, Van Beneden M, Verplaetse $R$, Croene $P$, Uyttendaele D, Verdonk R. Trunk asymmetries in a Belgian school population. Spine. 1982;7(6):555-562. doi:10.1097/00007632198211000-00008

46. Fok Q, Liu PY, Yip J, et al. School scoliosis screening in Hong Kong: trunk asymmetry of girls with scoliosis. MOJ Orthop Rheumatol. 2020;12(1):7-10. doi:10.15406/mojor.2020.12.00506

47. Yang L, Lu X, Yan B, Huang Y. Prevalence of abnormal body posture among Chinese children and adolescents: a large population $(158,584)$-based cross-sectional study. Eurasian $J$ Med Oncol. 2020;4(1):71-78. doi:10.14744/ejmo.2020.49640

48. Kwok G, Yip J, Cheung MC, Yick KL. Evaluation of myoelectric activity of paraspinal muscles in adolescents with idiopathic scoliosis during habitual standing and sitting. Biomed Res Int. 2015;2015:958450. doi:10.1155/2015/958450

49. Kwok G, Yip J, Yick KL, et al. Postural screening for adolescent idiopathic scoliosis with infrared thermography. Sci Rep. 2017;7 (1):14431. doi:10.1038/s41598-017-14556-w

50. Huang SC. Cut-off point of the scoliometer in school scoliosis screening. Spine. 1997;22(17):1985-1989. doi:10.1097/00007632199709010-00007

51. Gandek B, Ware JE. Methods for Validating and norming translations of health status questionnaires. J Clin Epidemiol. 1998;51 (11):953-959. doi:10.1016/S0895-4356(98)00086-9

52. Chen CY, Storr CL. Alcohol use and health-related quality of life among youth in Taiwan. $J$ Adolesc Heal. 2006;39(5):752.e9-752.e16. doi:10.1016/j.jadohealth.2006.04.019
53. Jörngården A, Wettergen L, von Essen L. Measuring health-related quality of life in adolescents and young adults: Swedish normative data for the SF-36 and the HADS, and the influence of age, gender, and method of administration. Health Qual Life Outcomes. 2006;4 (1):91. doi:10.1186/1477-7525-4-91

54. Lin Y, Yu Y, Zeng J, Zhao X, Wan C. Comparing the reliability and validity of the SF-36 and SF-12 in measuring quality of life among adolescents in China: a large sample cross-sectional study. Health Qual Life Outcomes. 2020;18(1):360. doi:10.1186/s12955-020-01605-8

55. Ware JE, Kosinski M, Gandek B, et al. The factor structure of the SF-36 Health Survey in 10 countries. J Clin Epidemiol. 1998;51 (11):1159-1165. doi:10.1016/S0895-4356(98)00107-3

56. Cheung MC, Yip J, Wong CSH. Quality of life among young female adolescents with regular daily use of electronic/video games in Hong Kong. Paper Presented at the IISES International Academic Conference; 2019 May 21-24; London, United Kingdom.

57. Cheung MC, Yip J, Wong CSH. Influence of computer and smartphone usage on quality of life in young female adolescents in Hong Kong. Paper Presented at 2019 International Symposium on Education and Psychology (ISEP 2019); 2019 Apr 1-3; Fukuoka, Japan.

58. Stiglic N, Viner RM. Effects of screentime on the health and well-being of children and adolescents: a systematic review of reviews. BMJ Open. 2019;9(1):e023191. doi:10.1136/bmjopen-2018-023191

59. Hakala PT, Saarni LA, Punamäki RL, Wallenius MA, Nygård C-H, Rimpelä AH. Musculoskeletal symptoms and computer use among Finnish adolescents - pain intensity and inconvenience to everyday life: a cross-sectional study. BMC Musculoskelet Disord. 2012;13 (1):41. doi:10.1186/1471-2474-13-41

60. Hakala PT, Rimpelä AH, Saarni LA, Salminen JJ. Frequent computer-related activities increase the risk of neck-shoulder and low back pain in adolescents. Eur J Public Health. 2006;16(5):536-541. doi:10.1093/eurpub/ck1025

61. Silva AG, Sa-Couto P, Queirós A, Neto M, Rocha NP. Pain, pain intensity and pain disability in high school students are differently associated with physical activity, screening hours and sleep. BMC Musculoskelet Disord. 2017;18(1):194. doi:10.1186/s12891-017-1557-6

62. Ng KC, Wu LH, Lam HY, et al. The relationships between mobile phone use and depressive symptoms, bodily pain, and daytime sleepiness in Hong Kong secondary school students. Addict Behav. 2020;101:105975. doi:10.1016/j.addbeh.2019.04.033

63. Shan Z, Deng G, Li J, Li Y, Zhang Y, Zhao Q. Correlational analysis of neck/shoulder pain and low back pain with the use of digital products, physical activity and psychological status among adolescents in Shanghai. PLoS One. 2013;8(10):e78109. doi:10.1371/journal.pone.0078109

64. Minoo D, Nasser B, Mahmood S. Prevalence and causes of postural deformities in upper and lower extremities among 9-18 years old school female in Golestan province. Eur J Exp Biol. 2013;3(6):115-121.

65. Meziat Filho N, Coutinho ES, Azevedo e Silva G. Association between home posture habits and low back pain in high school adolescents. Eur Spine J. 2015;24(3):425-433. doi:10.1007/s00586014-3571-9

66. Sjøgaard G, Lundberg U, Kadefors R. The role of muscle activity and mental load in the development of pain and degenerative processes at the muscle cell level during computer work. Eur J Appl Physiol. 2000;83(2-3):99-105. doi:10.1007/s004210000285

67. Brink Y, Louw Q, Grimmer K, Jordaan E. The relationship between sitting posture and seated-related upper quadrant musculoskeletal pain in computing South African adolescents: a prospective study. Man Ther. 2015;20(6):820-826. doi:10.1016/j.math.2015.03.015

68. Arienti C, Buraschi R, Donzelli S, Zaina F, Pollet J, Negrini S. Trunk asymmetry is associated with dominance preference: results from a cross-sectional study of 1029 children. Braz J Phys Ther. 2019;23 (4):324-328. doi:10.1016/j.bjpt.2018.08.005

69. Grivas TB, Vasiliadis ES, Polyzois VD, Mouzakis V. Trunk asymmetry and handedness in 8245 school children. Pediatr Rehabil. 2006;9(3):259-266. doi:10.1080/10428190500343027 


\section{Publish your work in this journal}

Patient Preference and Adherence is an international, peer-reviewed, open access journal that focusing on the growing importance of patient preference and adherence throughout the therapeutic continuum. Patient satisfaction, acceptability, quality of life, compliance, persistence and their role in developing new therapeutic modalities and compounds to optimize clinical outcomes for existing disease states are major areas of interest for the journal. This journal has been accepted for indexing on PubMed Central. The manuscript management system is completely online and includes a very quick and fair peer-review system, which is all easy to use. Visit http:// www.dovepress.com/testimonials.php to read real quotes from published authors. 